\title{
Microwave assisted heterogeneous catalysis: effects of varying oxygen concentrations on the oxidative coupling of methane
}

\author{
Binghua Ni $\cdot$ Colleen Lee $\cdot$ Run-Cang Sun • \\ Xunli Zhang
}

Received: 20 April 2009/Accepted: 29 September 2009/Published online: 3 November 2009 (C) Akadémiai Kiadó, Budapest, Hungary 2009

\begin{abstract}
The oxidative coupling of methane was investigated over alumina supported $\mathrm{La}_{2} \mathrm{O}_{3} / \mathrm{CeO}_{2}$ catalysts under microwave dielectric heating conditions at different oxygen concentrations. It was observed that, at a given temperature using microwave heating, selectivities for both ethane and ethylene were notably higher when oxygen was absent than that in oxygen/methane mixtures. The differences were attributed to the localised heating of microwave radiation resulting in temperature inhomogeneity in the catalyst bed. A simplified model was used to estimate the temperature inhomogeneity; the temperature at the centre of the catalyst bed was $85^{\circ} \mathrm{C}$ greater than that at the periphery when the catalyst was heated by microwaves in a gas mixture with an oxygen concentration of $12.5 \%(\mathrm{v} / \mathrm{v})$, and the temperature difference was estimated to be $168{ }^{\circ} \mathrm{C}$ in the absence of oxygen.
\end{abstract}

Keywords Microwave heating $\cdot$ Methane $\cdot$ Oxidative coupling

\section{B. Ni}

College of Chemistry and Chemical Engineering, Xi' an Shiyou University,

Xi'an 710065, China

C. Lee $\cdot$ X. Zhang

Department of Chemistry, Imperial College of Science, Technology and Medicine,

South Kensington, London SW7 2AY, UK

R.-C. Sun

College of Material Science and Engineering, Beijing Forestry University,

Beijing 100083, China

X. Zhang ( $\bowtie)$

School of Engineering Sciences, University of Southampton,

Southampton SO17 1BJ, UK

e-mail: XL.Zhang@soton.ac.uk 


\section{Introduction}

The conversion of methane, which is the major constituent of natural gas, into value-added chemicals has increasingly received attention in recent years [1-9]. Among the processes studied, oxidative coupling of methane (OCM) has shown a promising alternative route to convert methane directly into higher hydrocarbons [1-7], while extensive studies has been focused on converting methane into synthesis gas $[8,9]$, which can then be converted to higher hydrocarbons through the Fischer-Tropsch chemistry [9]. In the OCM process, methane and oxygen are generally fed over a metal or metal oxide catalyst at moderate temperatures (500 $800{ }^{\circ} \mathrm{C}$ ) to produce mainly ethane and ethylene. The majority of the previous studies on OCM have been focused on the development of catalysts ranging from metals to rare-earth metal oxides, and this still dominates the current relevant work [1-5]. The overall process has been found to be endothermic and energy intensive although the OCM reaction itself is highly exothermic when two methyl radicals are coupled after the abstraction of one hydrogen atom from the methane molecule [2].

Over the last two decades, the application of microwave radiation as a remote heating source to heterogeneous catalytic reaction systems has attracted intense interest [10-12]. Early work on OCM reactions using microwave heating has been conducted by Chen et al. [13] using proton conductive catalysts. The comparison of microwave radiation with conventional heating in the OCM process has been carried out by Bond et al. using a number of basic oxides [14]. The results from all of the catalysts tested showed that microwaves applied to the reaction resulted in $\mathrm{C}_{2}$ formation being attained at much lower temperatures with increased selectivity. The significant reduction in reaction temperature exceeds all attempts that have been made so far to improve catalyst activity when the conventional heating method is used. In addition, an increased ratio of ethylene to ethane in products, which is desirable, has been observed under microwave heating conditions $[13,15,16]$. Roussy et al. [15] have revealed an enhancement in higher hydrocarbons selectivity in OCM over microwave irradiated catalysts. Wan et al. [16] used pulsedmicrowave radiation to study the reaction of methane in the absence of oxygen. The reaction has been performed over a series of nickel catalysts, and the product distribution appeared to be affected by both the catalyst used and the power and frequency of the microwave pulses. In the study conducted by Chen et al. [13] with rare-earth oxide catalysts, a change in both product selectivity and product species formed was also found when compared to the conventionally heated reaction.

In our previous study [6] the OCM reaction was investigated by comparing microwave dielectric heating and conventional heating methods. The catalysts used under different conditions were examined with a range of catalyst characterization techniques. By comparison, a significant difference was observed in the products detected using microwave heating at measured temperatures about $250{ }^{\circ} \mathrm{C}$ lower than those observed with conventional heating when methane was converted into $\mathrm{C}_{2}$ hydrocarbons in the absence of oxygen. This increase in reaction rate was attributed to the localized heating of catalysts. In this paper, we report further investigations into the OCM reaction over alumina supported $\mathrm{La}_{2} \mathrm{O}_{3} / \mathrm{CeO}_{2}$ catalysts under microwave dielectric heating conditions. Emphasis has been placed on the effect of 
varying oxygen concentration in the feed gas mixture in terms of methane conversion and $\mathrm{C}_{2}$ product selectivity. The temperature variation in the catalyst bed during microwave heating has been theoretically analyzed and a heat transfer model has been developed in order to estimate the temperature distribution quantitatively.

\section{Experimental}

Experimental apparatus and operation

The catalytic reaction was carried out with a laboratory-scale, continuous flow reactor system equipped with facilities for both microwave and conventional heating [6, 17]. Briefly, a tubular packed-bed quartz reactor (inner diameter, $10 \mathrm{~mm}$ ) was placed in either a cylindrical microwave cavity or a conventional furnace. A directional coupler was incorporated into the co-axial microwave guide so that reflected microwave power from the cavity could be measured. The reflected power was minimized by tuning the cavity with its two adjustable tuners. The catalyst bed temperature was monitored with an Accufiber optical thermometer (Model 10, Luxtron) which was placed at the centre of the catalyst bed within the microwave fields. The optical fibre thermometer was calibrated against a chromel/ alumel thermocouple (which was also used in the conventional furnace) prior to the catalytic reactions. All the catalytic reactions were carried out under atmospheric pressure by introducing oxygen/methane/argon mixtures through the $(0.5 \mathrm{~g})$ catalyst bed in a temperature range of $400-1,000{ }^{\circ} \mathrm{C}$.

The composition of the feed gas mixture was varied by changing the ratio of oxygen to methane whilst both the flow rates of the inert carrier gas argon and that of the overall gas flow were kept constant giving an operating gas hourly space velocity (GHSV) of 4,600 $\mathrm{h}^{-1}$ (GHSV was defined as total hourly volumetric flow rate of the gaseous feed per volume of the catalytic bed). The three gas mixture flow ratios used in the experiments were oxygen/methane/argon $=7.5: 22.5: 30 \mathrm{~mL} \mathrm{~min}^{-1}$, 3.75:26.25:30 $\mathrm{mL} \mathrm{min}^{-1}$ and 0:30:30 $\mathrm{mL} \mathrm{min}^{-1}$, which correspond to the overall oxygen concentration of $12.5 \%(\mathrm{v} / \mathrm{v}), 6.25 \%(\mathrm{v} / \mathrm{v})$ and $0 \%(\mathrm{v} / \mathrm{v})$, in order. ASM mass flow controllers (model AFC-260) were used to mix the feed gases in known proportions prior to reaction. Methane (purity 99.0\%) and oxygen (purity 99.6\%) in lecture cylinders were purchased from Aldrich. Argon (purified) in a standard cylinder was obtained from BOC Gas.

\section{Catalyst preparation and characterization}

The catalyst used in this study was $10 \% \mathrm{La}_{2} \mathrm{O}_{3}-20 \% \mathrm{CeO}_{2}$ supported on $\gamma$-alumina, which was prepared by a two-step wet co-impregnation technique. First, an appropriate amount of lanthanum salt $\left[\mathrm{La}\left(\mathrm{NO}_{3}\right)_{3} \cdot 6 \mathrm{H}_{2} \mathrm{O}\right]$ solution, that was calculated to produce $10 \%(\mathrm{wt})$ of $\mathrm{La}_{2} \mathrm{O}_{3}$ loading on the support, was added to the ground alumina $(1 \mathrm{~g}$, powder size: $157-178 \mu \mathrm{m})$. The impregnated alumina was then dried in a conventional furnace at atmospheric pressure where the temperature was gradually increased from $50{ }^{\circ} \mathrm{C}$ to $105^{\circ} \mathrm{C}$ over a period of $3 \mathrm{~h}$. This was 
followed by an isothermal heating period of $18 \mathrm{~h}$ at $105^{\circ} \mathrm{C}$. Once dried, the sample was calcined in an air flow for $2 \mathrm{~h}$ at $500{ }^{\circ} \mathrm{C}$. In the second stage, ceria was impregnated onto the supported sample obtained from the first impregnation with the appropriate amount of cerium salt $\left[\mathrm{Ce}\left(\mathrm{NO}_{3}\right)_{3} \cdot 6 \mathrm{H}_{2} \mathrm{O}\right]$ solution in a similar procedure used in the first step.

A combination of analytical techniques have been used in this study for the characterization of catalysts, including BET surface area measurement, X-ray powder diffraction (XRD) and scanning electron microscopy (SEM). The surface area was measured, before and after reaction, with a Micromeritics ASAP-2000 analyzer. The composition of the catalysts before and after reaction was determined using a PW1710 X-ray diffractometer (Phillips Electronic Instruments) with $\mathrm{Cu} \mathrm{K}_{\alpha}$ radiation. The surface structures of the catalysts were investigated by SEM with a JEOL (JSM-T 200) scanning microscope.

Gas analysis

The effluent gas from the reactor outlet after reaction was analyzed with a 16channel quadrupole mass spectrometer (QMS-200D, European Spectrometry Systems), which was connected to the atmospheric pressure part of the system via a set of differentially pumped needle valves. The relative sensitivity of the mass spectrometer to different gases was obtained by flowing calibrated gas mixtures through the reactor at room temperature in the absence of a catalyst and noting the intensities of the signals. This was done for $\mathrm{CH}_{4} / \mathrm{H}_{2} / \mathrm{Ar}, \mathrm{CO}_{2} / \mathrm{H}_{2} / \mathrm{Ar}$ and $\mathrm{CO} / \mathrm{H}_{2} / \mathrm{Ar}$ mixtures. The mass spectrometry data, together with the thermocouple measurements, were recorded by a real-time, computerized data acquisition system (Sensorlab V.5, Fisons Instrumens, Vacuum Generators Quadrupoles). The product gas mixture was also analyzed with gas chromatography (Perkin Elmer 8500 Gas Chromatograph) where the samples were collected with a syringe during the reaction. An FID detector was used and the column consisted of 5\% Fluocol phase on a 60/80 Carbopack B support. The main compounds analyzed by gas chromatography included methane, ethane and ethylene. The GC peaks were also calibrated using gas mixtures of known concentrations [6].

The percentage conversion of the total methane flow was determined by calculating the QMS mass 16 signals obtained during reaction and after the reaction was stopped by lowering the reactor temperature to room temperature. The ethane and ethylene selectivities were defined as the percentage of the reacted methane that has been converted to $\mathrm{C}_{2} \mathrm{H}_{6}$ and $\mathrm{C}_{2} \mathrm{H}_{4}$, respectively, and were calculated from the area under the gas chromatography traces.

\section{Results and discussion}

Catalyst characterization

The catalyst surface areas were measured before and after reactions at temperatures up to $900{ }^{\circ} \mathrm{C}$ with microwave heating. The measurements showed a reduction (from 
$67 \mathrm{~m}^{2} \mathrm{~g}^{-1}$ to $27 \mathrm{~m}^{2} \mathrm{~g}^{-1}$ ) in catalyst surface area after reaction when oxygen was present. The surface area of the sample measured after microwave heating without oxygen in the gas mixture was significantly small $\left(14 \mathrm{~m}^{2} \mathrm{~g}^{-1}\right)$.

The catalyst used was also examined using XRD technique before and after reactions. The diffraction pattern of the catalyst before undergoing reaction showed that $\gamma$-alumina and cerium oxide were the only crystalline phases detected. When the catalyst was microwave heated to $900{ }^{\circ} \mathrm{C}$ in an oxygen/methane/argon mixture with oxygen $(6.25 \% \mathrm{v} / \mathrm{v})$, additional sharp peaks were observed which corresponded to lanthanum or cerium aluminate. In contrast, when the catalyst was microwave heated to $850{ }^{\circ} \mathrm{C}$ in a methane/argon mixture (without oxygen), not only did the diffraction pattern show remarkably sharp aluminate peaks, but the size of the remaining cerium oxide peaks was also observed to be very much reduced. It was indicative that nearly all of the cerium oxide had been converted into aluminate.

SEM examination of the supported catalysts, before and after reactions, showed that the heat of reaction had caused the surface to become fused together, with surface cracks and holes appearing, and surface cracks were observed under all conditions. The holes were most prevalent in samples that had been heated in methane/argon mixtures by microwave heating, but some holes were also evident when oxygen was present. The origin of these holes is not clear but the fact that they are more numerous when oxygen is absent suggests that they may be connected with carbon formation and perhaps whisker growth.

\section{Methane conversion}

The experiments were conducted at three oxygen concentrations of $0 \%, 6.25 \%$ and $12.5 \%$ in the feed gas mixtures. Fig. 1a shows the methane conversion as a function of temperature using conventional heating method at three oxygen levels. It can be seen that the methane conversion increased with an increase in temperature for all oxygen concentrations. It was also observed that at a given temperature, the methane conversion decreased when the oxygen concentration was reduced.

When the reaction was carried out under microwave dielectric heating conditions, similarly, the methane conversion increased with temperature rising for all oxygen levels (Fig. 1b). However, the effect of varying oxygen concentration was found to be different from that using conventional heating. It can be seen that the methane conversion was notably higher when oxygen was absent than that of $6.25 \%$ oxygen, especially in the higher temperature range $\left(>750{ }^{\circ} \mathrm{C}\right)$.

It was also observed that, at low temperatures, the main products were $\mathrm{CO}_{2}$ and $\mathrm{H}_{2} \mathrm{O}$ but as the temperature was raised, the production of $\mathrm{CO}$ and $\mathrm{H}_{2}$ increased to become the predominant reaction at $900{ }^{\circ} \mathrm{C}$ and above. The results obtained were in line with the previous observations [6]. In general, the reaction of methane with oxygen at moderate temperatures produced mainly $\mathrm{CO}_{2}, \mathrm{CO}, \mathrm{H}_{2} \mathrm{O}$ and $\mathrm{H}_{2}$, whilst only a small percentage of methane resulted in $\mathrm{C}_{2}$ hydrocarbon formation. In the lower temperature range, the main products were $\mathrm{CO}_{2}$ and $\mathrm{H}_{2} \mathrm{O}$ but as the temperature rose, the percentage of $\mathrm{CO}$ and $\mathrm{H}_{2}$ increased to become the predominant reaction at $900{ }^{\circ} \mathrm{C}$ and above. The two main reactions were 

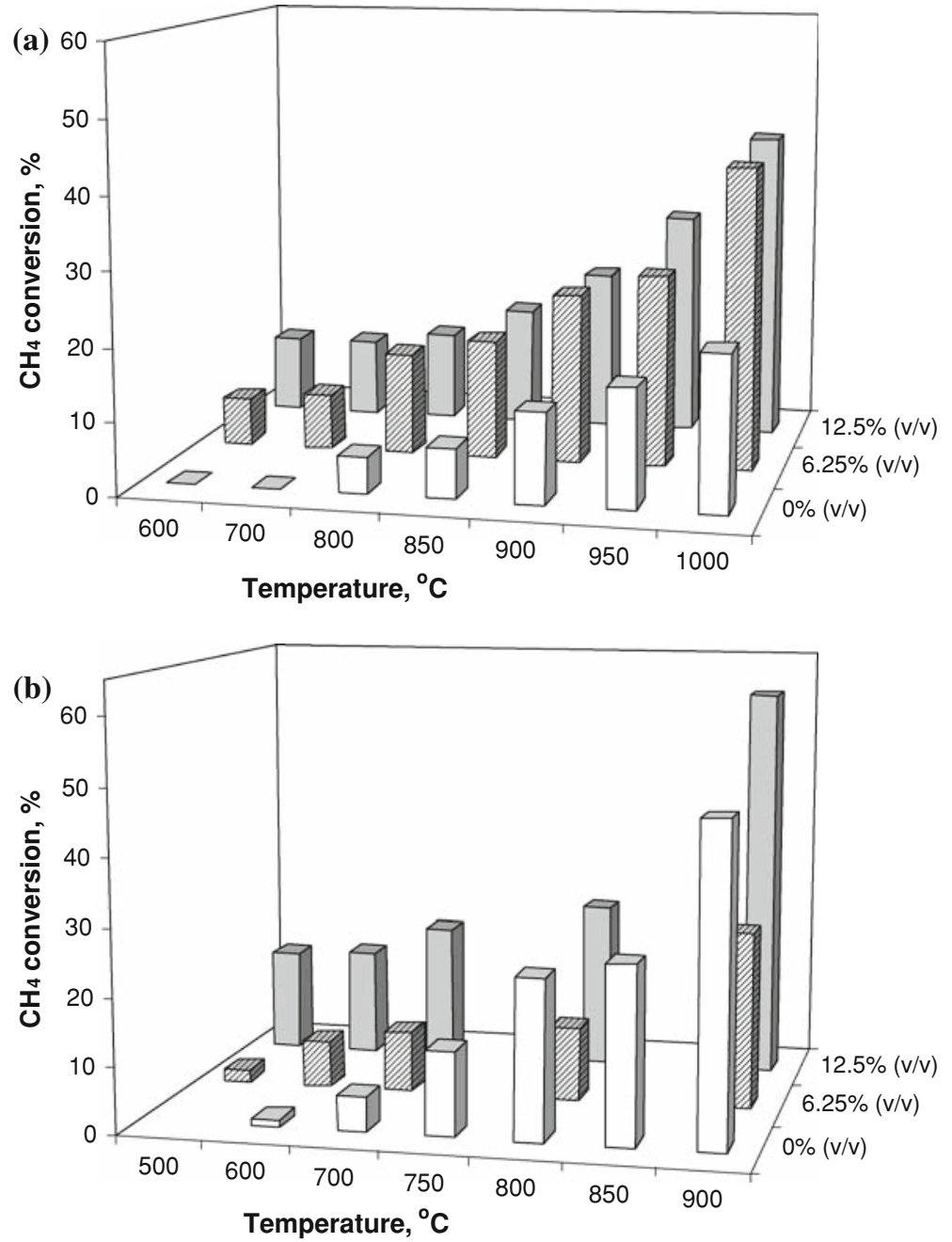

Fig. 1 Methane conversion vs temperature (a) using conventional heating and (b) under microwave heating conditions at three oxygen levels of $0 \%(\mathrm{v} / \mathrm{v}), 6.25 \%(\mathrm{v} / \mathrm{v})$ and $12.5 \%(\mathrm{v} / \mathrm{v})$

$$
\mathrm{CH}_{4}+2 \mathrm{O}_{2} \rightarrow \mathrm{CO}_{2}+2 \mathrm{H}_{2} \mathrm{O}
$$

and

$$
\mathrm{CH}_{4}+\frac{1}{2} \mathrm{O}_{2} \rightarrow \mathrm{CO}+2 \mathrm{H}_{2}
$$

The balance of the reactions occurring was affected by the temperature and also altered by the concentration of oxygen in the feed gas mixture. The product analysis showed that, in the presence of oxygen at a low level $\left(6.25 \% \mathrm{O}_{2}\right)$, nearly all of the oxygen was consumed under both heating conditions. Therefore, a higher conversion of methane was expected with an increase in the amount of oxygen in 
the gas flow $\left(12.5 \% \mathrm{O}_{2}\right)$. This methane conversion increase was observed for both heating methods but more significantly under microwave heating conditions (Fig. 1). By contrast, in the absence of oxygen when using microwave heating, a higher methane conversion was observed than that at $6.25 \% \mathrm{O}_{2}$ which was indicative of changes in the reaction route that, in turn, resulted in the product selectivity difference. The effect of varying oxygen concentration on product $\mathrm{C}_{2}$ selectivities is discussed in greater detail below.

\section{Product $\mathrm{C}_{2}$ selectivity}

Fig. 2 illustrates the selectivity of ethane and ethylene as a function of temperature at different oxygen levels under microwave dielectric heating conditions. It can be seen from Fig. 2a that the ethane production reached its maximum in the temperature range of $700-800{ }^{\circ} \mathrm{C}$; the highest selectivity of $20.8 \%$ was obtained at $700{ }^{\circ} \mathrm{C}$ in the absence of oxygen. The overall ethane selectivity in the absence of oxygen was also higher than that in oxygen/methane mixtures. In terms of ethylene selectivity, no ethylene was observed until the temperature reached $700{ }^{\circ} \mathrm{C}$ and the ethylene selectivity reached a maximum also in the temperature range of 700 $800{ }^{\circ} \mathrm{C}$ (Fig. 2b). It was found that in the presence of oxygen the ethylene selectivities were relatively low $(<8 \%)$ and there was little difference between the two oxygen levels. By contrast, a dramatic increase in ethylene production was observed in the absence of oxygen at temperatures above $700{ }^{\circ} \mathrm{C}$.

During the experiment using microwave heating without oxygen, it was also noticed that the amount of microwave radiation reflected by the catalyst tended to increase at high temperatures $\left(>850^{\circ} \mathrm{C}\right)$, showing that the dielectric property of the catalyst had changed which was likely a decrease in the dielectric loss, the ability of the material to transform microwave energy into heat. Further examination of the catalyst by XRD revealed that aluminates were formed, and the cerium oxide peaks became reduced in size, showing that most of the cerium oxide had reacted. Thus, the property change of the catalyst was likely associated with the reaction occurring above $850{ }^{\circ} \mathrm{C}$, when the catalyst was heated by microwaves in the absence of oxygen, resulting in the formation of cerium aluminate. This would explain the rise in reflection of the microwave radiation because cerium oxide has a relatively large dielectric loss and is the main component in the catalyst that absorbs microwaves. The change would also contribute to the variation of the product selectivity.

In the microwave heating experiments, the selectivity for hydrocarbon formation never rose above $30 \%$ and the greater part of the methane appeared to form carbon. It was evidenced by the observation that the samples were black at the end of the experiments whereas samples that had been heated in oxygen/methane mixtures were cream-colored.

The results obtained are in line with that observed by other researchers [18-21]. In the study by Marun et al. [18, 19] on the oligomerization of methane to higher hydrocarbons using microwave heating, they observed both arc formation and discharges produced by the catalyst. Ethane was found to be the major product at the 

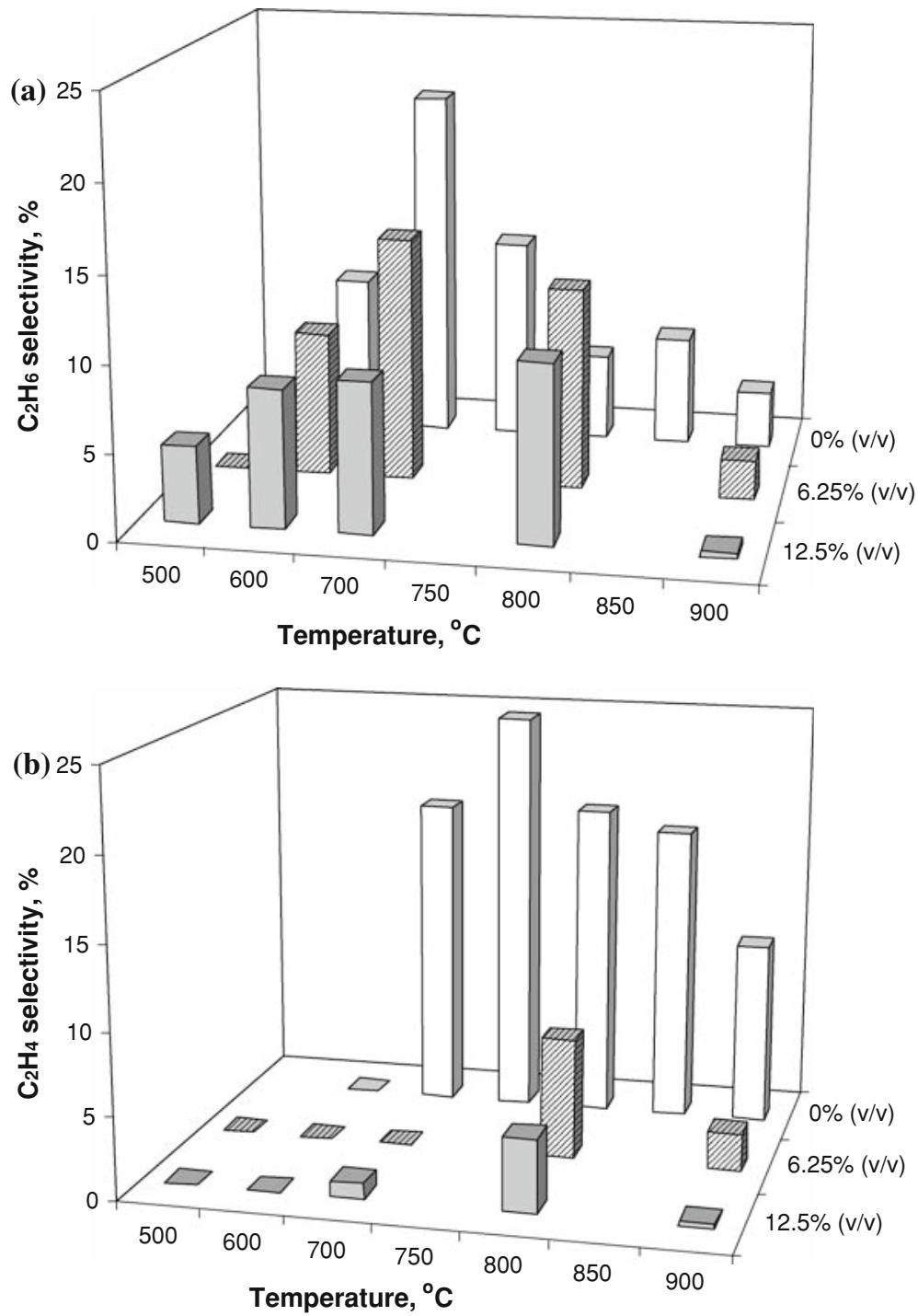

Fig. 2 (a) Ethane and (b) ethylene selectivity as a function of temperature under microwave heating conditions at three oxygen levels of $0 \%(\mathrm{v} / \mathrm{v}), 6.25 \%(\mathrm{v} / \mathrm{v})$ and $12.5 \%(\mathrm{v} / \mathrm{v})$

beginning of the reaction. However, when arc formation was noticeable, significant selectivity to ethylene was observed. This result is also in agreement with earlier data for the oligomerization of methane via microwave plasmas where Suib et al. $[20,21]$ found that the arcing process during microwave plasma catalysis of methane significantly affected the product selectivity. Suib et al. attributed this observation to the existence of a unique mechanism for time generation of nonthermodynamic equilibrium in discharges during catalytic reactions, leading to 
significant changes in activity and selectivity of the catalyst. Therefore, due to the significant similarities observed with the results obtained in the work here and the results obtained from the work reported by Marun et al. and Suib et al. it is plausible to conclude that, in the absence of oxygen, microwave plasma catalysis of methane was responsible for the increase in ethylene selectivity when the temperature reached $850{ }^{\circ} \mathrm{C}$.

For comparison, the product selectivities as a function of temperature using conventional heating are also shown (Fig. 3) for all three oxygen levels. For both ethane and ethylene selectivities in the presence of oxygen, similar trends were seen
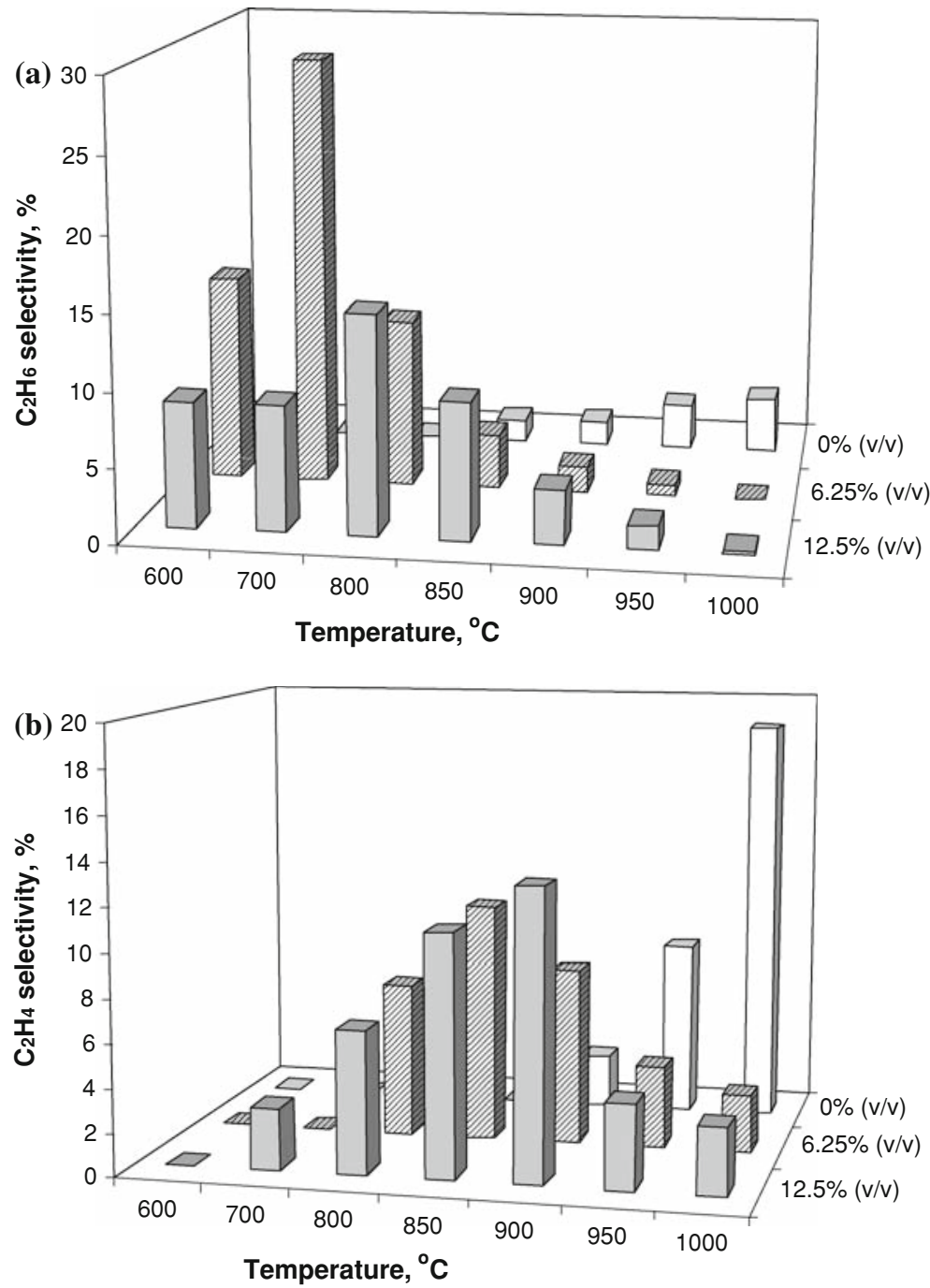

Fig. 3 (a) Ethane and (b) ethylene selectivity as a function of temperature using conventional heating at three oxygen levels of $0 \%(\mathrm{v} / \mathrm{v}), 6.25 \%(\mathrm{v} / \mathrm{v})$ and $12.5 \%(\mathrm{v} / \mathrm{v})$ 
with increasing temperature. However, significant differences were found in the absence of oxygen, which further supported the assumption that the microwave assisted process undertook different mechanism compared to the conventional heating process.

It was also observed that a high degree of reproducibility of reaction results could be reached without much difficulty under conventional heating conditions. However, under microwave heating conditions, the operational parameters required more careful monitoring and control in order to obtain reproducible results. That was mainly due to the complexity of microwave dielectric heating process. More detailed analysis of the microwave absorption process is described below.

Microwave power absorption

In the experiments of oxidative coupling of methane performed by means of microwave heating, the microwave radiation was relayed to the catalyst bed via a co-axial cable that was connected to the tunable microwave cavity. The microwave power output and reflected power were measured at different power levels applied for all the catalytic runs in order to determine the energy absorbed by the catalyst. For an insulated system that is assumed to be free of electromagnetic leakages, the microwave power absorbed by the catalyst bed can be determined by the difference between the input power and the reflected power measured.

Fig. 4a shows the absorbed microwave power by the supported catalyst as a function of temperature in oxygen/methane mixture and also in the absence of oxygen. It can be seen that, in general, the absorbed power increased with temperature rising and the increase in power tended to be smaller at higher temperatures indicating an increase in microwave heating efficiency. This is in agreement with the previous study where the dielectric loss of the catalyst generally increased with increasing temperature [22, 23].

It was also observed that a smaller amount of microwave power was absorbed when no oxygen was present in the gas mixture than that in the presence of oxygen. However, the fraction of input microwave power that was absorbed was also smaller without oxygen (Fig. 4b). This indicated that the catalyst heated in gas mixture without oxygen was more difficult to heat, requiring a relatively greater input power to achieve a given temperature. For both oxygen levels, an approximately linear relationship was found between the fraction of input microwave power and temperature.

Estimate of temperature variation in catalyst bed during microwave heating

\section{Derivation of formula}

It is well-known that in a conventional heating process heat enters the sample through its surface and is transferred towards the centre of the sample mainly by thermal conduction. During microwave heating, in contrast, the microwave power is dissipated in a dielectric and the electromagnetic energy is converted directly to heat 

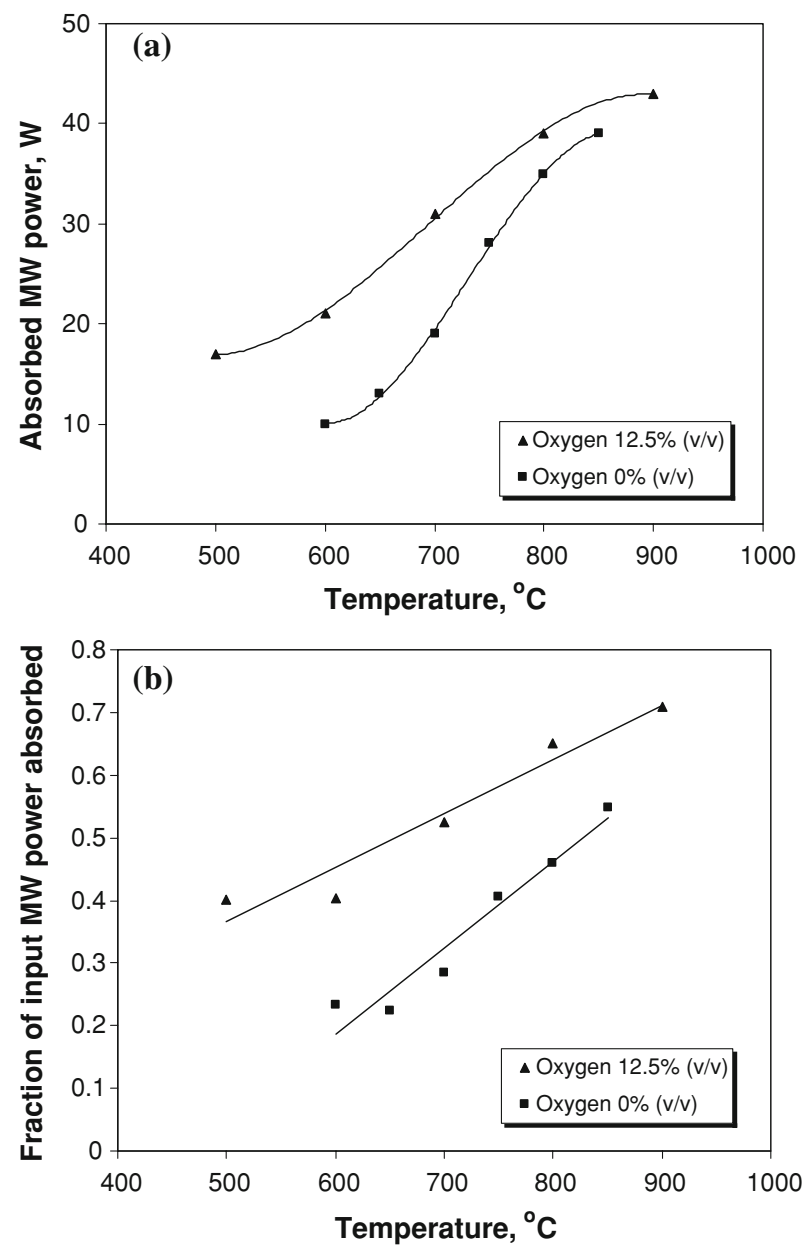

Fig. 4 (a) Absorbed microwave power and (b) fraction of input microwave power as a function of temperature with oxygen (filled triangles) at a concentration $12.5 \%(\mathrm{v} / \mathrm{v})$, and without oxygen (filled squares)

inside the sample which is generally referred to as volumetric heating. As a result, in the cylindrical catalytic reactor used in the study under microwave heating conditions, temperature gradients are necessarily created between the centre of the catalyst bed and the periphery [11]. Fig. 5 illustrates a cross section of the catalyst bed with a radius of $R$ and length $L$ where the input power per unit volume, $W$, is constant throughout the bed. In general cases $L>>R$, thus end effects are neglected in the calculations. The heat transfer across the boundaries shown in Fig. 5 is represented by the equations:

Heat transfer rate across the boundary at $r=-2 \pi r L \kappa(\mathrm{d} T / \mathrm{d} r)_{r=r}$ 
Fig. 5 Cross section of the cylindrical catalyst bed with a radius of $R$

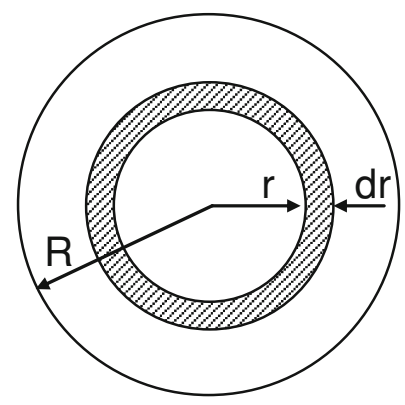

Heat transfer rate across the boundary at $r+\mathrm{d} r=-2 \pi(r+\mathrm{d} r) L \kappa(\mathrm{d} T / \mathrm{d} r)_{r=r+\mathrm{d} r}$

where $\kappa$ is the thermal conductivity of the catalyst bed. The heat generated per second by microwave absorption in the volume element between $r$ and $r+\mathrm{d} r$ is equal to $\alpha W 2 \pi r L \mathrm{~d} r$, where $\alpha$ is the fraction of the microwave input power that is absorbed. In the experiment, $\alpha$ was found to vary almost linearly with temperature (Fig. 4b). Hence $\alpha$ can be represented as a function of temperature $T$.

$$
\alpha=b T+c
$$

At the steady state, the rate of heat transfer from the sample is equal to the heat dissipated in the sample from the applied microwave radiation.

$$
-2 \pi(r+\mathrm{d} r) L \kappa(\mathrm{d} T / \mathrm{d} r)_{r=r+\mathrm{d} r}+2 \pi r L \kappa(\mathrm{d} T / \mathrm{d} r)_{r=r}=\alpha W 2 \pi r L \mathrm{~d} r
$$

This equation reduces to

$$
\alpha W=-\kappa\left[\mathrm{d}^{2} T / \mathrm{d} r^{2}+1 / r(\mathrm{~d} T / \mathrm{d} r)\right]
$$

By substituting $\alpha=b T+c$, it becomes

$$
\mathrm{d}^{2} T / \mathrm{d} r^{2}+1 / r(\mathrm{~d} T / \mathrm{d} r)+W b T / \kappa=-W c / \kappa
$$

With the further substitutions of $p^{2}=W b / \kappa$ and $q=c / b$ into Eq. 8, this equation can be rewritten as

$$
\mathrm{d}^{2} T / \mathrm{d} r^{2}+1 / r(\mathrm{~d} T / \mathrm{d} r)+p^{2} T / \kappa=-p^{2} q
$$

The solution to this differential equation, the heat transfer model, can be obtained in terms of the Bessel function $J_{0}(\mathrm{pr})$ of zero order:

$$
T=A J_{0}(p r)-q
$$

where $A$ is a constant that has to be determined.

\section{Application of heat transfer model to experimental data}

Catalyst heated in a gas mixture with oxygen concentration $12.5 \%(\mathrm{v} / \mathrm{v}) \quad$ To obtain an approximation of the temperature at the centre of the catalyst, the constant, $A$, in Eq. 10 must first be determined. As shown in Fig. 4b, the fraction of the input 
microwave power that was absorbed varied approximately linearly with temperature. The values of $b$ and $c$ in Eq. 5 were found to be 0.00085 and -0.065 , respectively.

For the catalyst bed used in this work, $L=1 \mathrm{~cm}$. At the temperature of $900{ }^{\circ} \mathrm{C}$, the input microwave power was $64 \mathrm{~W}$ therefore, the input microwave power per unit volume, $W$, can be determined.

$$
W=\text { input power } / \pi R^{2} L=43 / \pi(0.5)^{2}=54.7 \mathrm{~W} \mathrm{~cm}^{-3}
$$

Since the data for the thermal conductivity, $\kappa$, of the catalyst is not available, values quoted in the literature for both sintered and compressed alumina were considered instead. For sintered alumina at $700{ }^{\circ} \mathrm{C}$, a value of $8 \mathrm{~W} \mathrm{~m}^{-1} \mathrm{~K}^{-1}$ was quoted [24]. For compressed alumina at $430{ }^{\circ} \mathrm{C}$, a value of $3.1 \mathrm{~W} \mathrm{~m}^{-1} \mathrm{~K}^{-1}$ was used [25]. It has been observed that after moderate heating, the catalyst started to show some signs of adhesion between the particles as evidenced by the SEM and surface area measurements. Therefore, the catalyst is expected to have a fairly high thermal conductivity but not as high as that of sintered alumina. Hence, for the purposes of calculation, the lower value quoted here is used, rounded off to $3 \mathrm{~W} \mathrm{~m}^{-1} \mathrm{~K}^{-1}$.

When the values of $W, b, c$ and $k$ are substituted into the expressions for $p$ and $q$, we obtain

$$
p=1.24 \mathrm{~cm} \text {, and } q=76.5 \mathrm{~K}
$$

At the periphery of the catalyst, $r=0.5$ and $J_{0}(1.24 \times 0.5)=0.92$. By taking the temperature of the periphery to be the measured temperature, $900{ }^{\circ} \mathrm{C}$, the constant $A$ was calculated to be $1061.4 \mathrm{~K}$. The temperature at the centre of the catalyst, where $r=0$, was then found to be $984.9{ }^{\circ} \mathrm{C}$.

Thus, according to this calculation, the temperature at the centre of the catalyst is $85^{\circ} \mathrm{C}$ greater than the temperature at the periphery. Although this calculation can only be illustrative because the actual thermal conductivity of the catalyst material is not known, there is still reasonable agreement with the experimental data where the difference between the temperature measured by the optical probe and that deduced from $\mathrm{C}_{2}$ hydrocarbon production was never more than $100{ }^{\circ} \mathrm{C}$.

Catalyst heated in a gas mixture without oxygen Similarly, the fraction of the input microwave power that was absorbed varied approximately linearly with temperature when the reaction was carried out without oxygen. However, the values obtained were considerably lower than those observed when the catalyst was heated in methane/oxygen mixture. It was also observed that at $850{ }^{\circ} \mathrm{C}$, the input microwave power was much higher at $87 \mathrm{~W}$ and the input microwave power per unit volume, $W$, was calculated to be $111 \mathrm{~W} \mathrm{~cm}^{-3}$. The parameters $p=2.27 \mathrm{~cm}$ and $q=$ $-457 \mathrm{~K}$ were also obtained from similar calculations carried out previously. At the periphery of the catalyst, $r=0.5$, the Bessel function $J_{0}(2.27 \times 0.5)=0.7$ and $A=561.1 \mathrm{~K}$ was calculated. Following the same procedures used previously, the temperature at the centre of the catalyst, $r=0$, was found to be $1018.4{ }^{\circ} \mathrm{C}$, which is $168{ }^{\circ} \mathrm{C}$ higher than at the periphery. 
It has been demonstrated that the power absorbed by a dielectric is determined by a combination of the electromagnetic field applied, the volume of the sample and the dielectric property $[11,22,23]$. Furthermore, it has been shown that in the identical reactor system small changes in the dielectric loss characteristics of the catalyst can result in significant differences in the temperature gradient established within the catalyst [22]. It can be seen from Fig. 4 that, when the catalyst was heated by microwave radiation in the absence of oxygen, a much higher input power was required to reach a particular temperature than when the catalyst was heated with oxygen. This is indicative that a change had occurred in the dielectric loss characteristics of the catalyst. Consequently, these changes appeared to give rise to thermal instability, resulting in the central region of the catalyst being heated to a much higher temperature than the outer regions of the catalyst.

There are two possible ways in which the catalyst was altered when oxygen was absent.

(i) The tendency for carbon to deposit on the catalyst heated without oxygen might enhance the absorption of microwave radiation. However, this seems to be a rather unlikely explanation for the observed behavior for two reasons. In the first instance, hot spots appear to be necessary to explain the formation of ethane at $600{ }^{\circ} \mathrm{C}$ when there is little, if any, carbon deposited on the catalyst. Second, the catalyst becomes difficult to heat by adsorption of microwave radiation after heating to high temperatures. If carbon was a primary microwave radiation absorber, it is difficult to see how it could become deactivated at high temperatures.

(ii) Tetravalent cerium oxide, $\mathrm{CeO}_{2}$ is known to change color and darken when heated in the absence of oxygen. This is thought to be due to the formation of a mixed valency compound containing both trivalent and tetravalent cerium in the same crystal [26]. Therefore, the formation of the trivalent oxide, $\mathrm{Ce}_{2} \mathrm{O}_{3}$ is very likely under prolonged heating conditions at elevated temperatures in the absence of oxygen. This oxide must be produced at some stage prior to the formation of cerium aluminate according to the following scheme:

$$
\begin{gathered}
2 \mathrm{CeO}_{2} \rightarrow \mathrm{Ce}_{2} \mathrm{O}_{3}+\frac{1}{2} \mathrm{O}_{2} \\
\mathrm{Ce}_{2} \mathrm{O}_{3}+\mathrm{Al}_{2} \mathrm{O}_{3} \rightarrow 2 \mathrm{CeAlO}_{3}
\end{gathered}
$$

$\mathrm{CeO}_{2}$ is known to be stable in air up to very high temperatures and in experimental runs where oxygen was present in the gas flow, this would be sufficient to prevent its reduction to the lower oxide. When $\mathrm{Ce}_{2} \mathrm{O}_{3}$ has a slightly lower dielectric loss factor but a higher temperature coefficient than $\mathrm{CeO}_{2}[27,28]$, the analysis is then in line with the experimental findings which also explains why large differences in the temperature gradients are established within the catalyst when oxygen was absent. 


\section{Conclusions}

The oxidative coupling of methane was investigated over alumina supported $\mathrm{La}_{2} \mathrm{O}_{3}$ / $\mathrm{CeO}_{2}$ catalysts under microwave dielectric heating conditions where the feed gas composition was varied, and was compared to conventional heating method. It was found that at a given temperature using conventional heating, the methane conversion decreased when the oxygen concentration was reduced. Under microwave heating conditions, however, the methane conversion was notably higher when oxygen was absent than that of $6.25 \%$ oxygen, especially in the higher temperature range $\left(>750{ }^{\circ} \mathrm{C}\right)$. Higher selectivities for both ethane and ethylene were observed in the absence of oxygen using microwave heating compared to that with oxygen. The observation was believed to be due to the localized heating of microwave radiation resulting in temperature inhomogeneity in the catalyst bed. At its extreme, this likely led to methane plasma formation and arcing with the catalyst bed in the absence of oxygen. It was estimated that the temperature at the centre of the catalyst was $85{ }^{\circ} \mathrm{C}$ greater than that at the periphery when the catalyst heated by microwaves in gas mixture with an oxygen concentration $12.5 \%(\mathrm{v} / \mathrm{v})$. This temperature difference was calculated to be $168{ }^{\circ} \mathrm{C}$ in the absence of oxygen. Both experimental observation and theoretical analysis showed that the magnitude of the temperature gradient created within the catalyst bed can vary enormously depending on the dielectric loss characteristics of the catalyst whilst the dielectric loss generally increases with rising temperature. Heating the catalyst using microwave dielectric heating in the absence of oxygen likely alters the dielectric loss characteristics pronouncing the temperature difference between the centre and the periphery of the catalyst.

\section{References}

1. Takanabe K, Iglesia E (2008) Angew Chem Int Ed 47:7689

2. Chua YT, Mohamed AR, Bhatia S (2008) Appl Catal A: Gen 343:142

3. Chen FQ, Zheng W, Zhu N, Cheng DG, Zhang XL (2008) Catal Lett 125:348

4. Fakhroueian Z, Farzaneh F, Afrookhteh N (2008) Fuel 87:2512

5. Machocki A, Jezior R (2008) Chem Eng J 137:643

6. Zhang XL, Lee CSM, Mingos DMP, Hayward DO (2003) Appl Catal A: Gen 249:151

7. Wonihl C, Youngsoon B, Moon SK, Kim YC (2002) Catal Today 74:207

8. Koni D, Weber WH, Poindexter BD, McBride JR, Graham GW, Otto K (1994) Catal Lett 29:329

9. Rostrup-Nielsen JR (1984) In: Anderson JR, Boudart M (eds) Catalysis, science and technology, vol 5. Springer, Berlin, Ch. 1

10. Nilsson P, Ofsson K, Larhed M (2006) Top Curr Chem 266:103

11. Zhang XL, Hayward DO (2006) Inorg Chim Acta 359:3421

12. Nelson WM (2003) Green solvents for chemistry. Oxford University Press, Inc., New York

13. Chen C, Hong P, Dai S, Kan J (1995) J Chem Soc, Faraday Trans 92:1179

14. Bond G, Moyes RB, Whan DA (1993) Catal Today 17:427

15. Roussy G, Marchal E, Thiebaut JM, Kiennemann A, Maire G (1997) Fuel Process Technol 50:261

16. Wan JKS, Tse MY, Husby H, Depew MC (1990) J Microwave Power Electromagn Energy 25:32

17. Zhang XL, Hayward DO, Mingos DMP (1999) Chem Commun 975

18. Marun C, Suib SL, Dery M, Harrison JB, Kablaoui MJ (1996) J Phys Chem 100:17866

19. Marun C, Conde LD, Suib SL (1999) J Phys Chem A 103:4332

20. Suib SL, Zerger RP (1993) J Catal 139:383 
21. Suib SL (1998) CatTech 2:75

22. Zhang XL, Hayward DO, Mingos DMP (2001) Ind Eng Chem Res 40:2810

23. Zhang XL, Hayward DO, Mingos DMP (2002) Catal Lett 84:225

24. Powell RL, Childs GE (1972) In: Gray DE (ed) American Institute of Physics Handbook. McGrawHill, New York

25. Carberry JJ (1976) Chemical and catalytic reaction engineering. McGraw-Hill, New York

26. Moeller T (1965) The chemistry of lanthanides. Chapman and Hall, London

27. Yamamoto T, Momida H, Hamada T, Uda T, Ohno T (2005) Thin Solid Films 486:136

28. Anjana PS, Sebastian MT, Suma MN, Mohanan P (2008) Int J Appl Ceram Technol 5:325 